\title{
Tertiary and salvage rhinoplasties using the open rhinoplasty approach
}

\author{
Bernd R Neu MD FRCSC \\ Division of Plastic Surgery, North York General Hospital, Toronto, Ontario
}

Bernd R Neu. Tertiary and salvage rhinoplasties using the open rhinoplasty approach. Can J Plast Surg 1999;7(1):15-22.

This paper reviews the results of 26 tertiary and salvage rhinoplasties, all managed by the open technique. Typically, the endonasal approach has been recommended for these difficult cases because of concerns with skin viability, and the belief that scarred nasal skin will not redrape satisfactorily. Minimal undermining has also been promoted to reduce the risk of graft shifting. Each deformity presented in this review was managed with an open exposure. There were no problems with skin viability or redraping. Cartilage grafts were required less often, and when needed, were sewn precisely into place. Tissue swelling could take 12 to 18 months to settle. This paper reinforces the need for careful preoperative planning. Potential surgical pitfalls are examined.

Key Words: Cleft lip nose, Open rhinoplasty, Salvage rhinoplasty, Secondary rhinoplasty, Tertiary rhinoplasty, Septoplasty

\section{Rhinoplasties tertiaires et de sauvetage à l'aide d'une technique ouverte}

RÉSUMÉ : Cet article passe en revue les résultats de 26 rhinoplasties tertiaires et de sauvetage, toutes effectuées par technique ouverte. De façon typique, l'approche endonasale a été recommandée pour ces cas difficiles en raison d'inquiétudes quant à la viabilité cutanée et en raison d'une crainte que le tissu cutané nasal cicatriciel ne se redrape pas de façon satisfaisante. On a également vu à réduire le risque de migration de la greffe. Chaque déformation présentée dans ce survol a été traitée au moyen d'une exposition ouverte. On n'a noté aucun problème quant à la viabilité cutanée ou quant au redrapage. Les greffes de cartilage ont été moins souvent nécessaires et au besoin, ont été cousues précisément en place. L'œdème tissulaire pouvait prendre de 12 à 18 mois pour se résorber. Cet article souligne la nécessité d'une planification pré-opératoire soigneuse. On se penche également sur les obstacles chirurgicaux potentiels.

$\mathrm{T}$ The versatility of the open approach has made it a well accepted technique for routine rhinoplasties. However, there is less enthusiasm in applying the concept to salvage or tertiary nasal procedures. Reluctance to apply the open rhinoplasty approach for these procedures stems largely from concerns with skin viability and redraping after wide undermining. The more limited endonasal dissection is also favoured because of the need for small subcutaneous pockets, which prevent grafts from shifting.

This paper reviews 26 salvage or tertiary rhinoplasties. All patients were managed with the open approach over a

This paper was presented at the 49th Annual Meeting of the Canadian Society of Plastic Surgeons, June 10, 1995, Saskatoon, Saskatchewan

Correspondence and reprints: Dr BR Neu, One Medical Place, 20 Wynford Drive, Suite 216, Toronto, Ontario M3C $1 S 4$.

Telephone 416-447-6176, fax 416-447-5750, bernd.neu@sympatico.ca three-year period. The clinical considerations and preoperative planning are discussed. Potential pitfalls in skin flap elevation are examined, and the specific dissection techniques for the nasal tip, dorsum and septum are described.

Four basic types of repair are recognized. In some patients, the repair is primarily a release of contracted and scarred cartilages, with or without the use of spreader grafts (1). In others, the repositioning and reshaping of displaced and misshapen cartilages is the primary focus (2). More serious problems require replacement of cartilage and bone segments that were removed in previous operations (3). Some tertiary congenital problems such as cleft lip nose require reconstruction of nasal elements that are lacking (4). While each case presented has a primary focus of repair, there is frequent overlap. A representative example of each of the four types of repair is presented. 

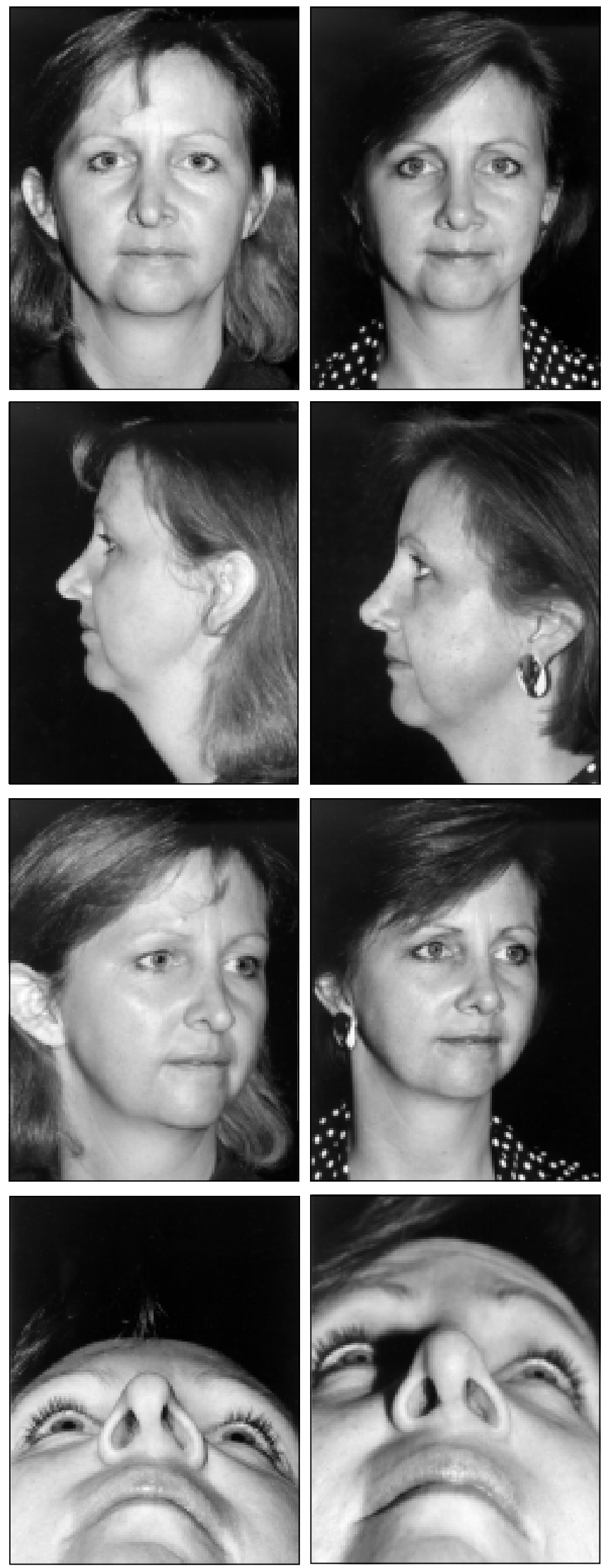

Figure 1) Case 1. Release of contracted cartilages. Left Preoperative view. Right Postoperative view
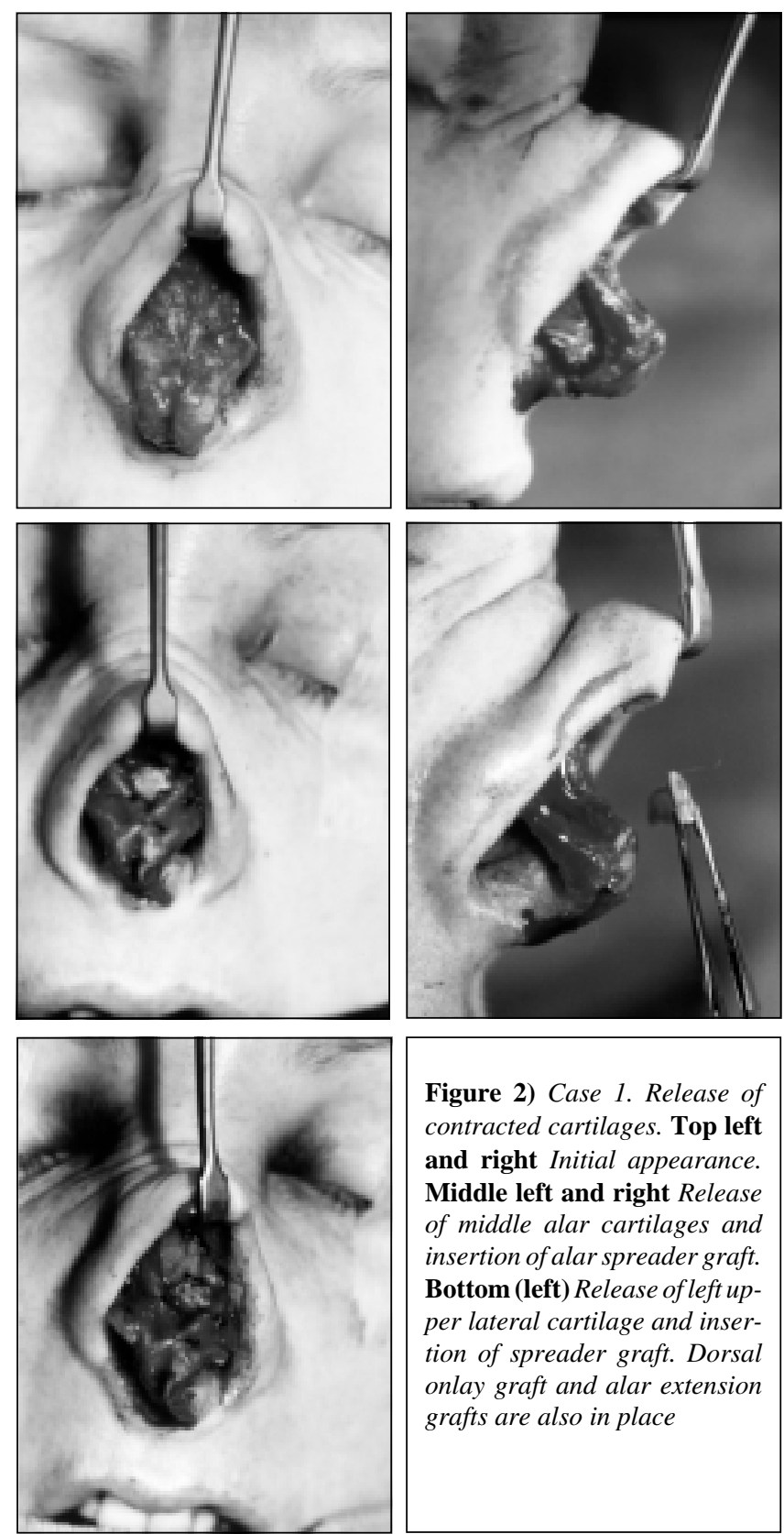

Figure 2) Case 1. Release of contracted cartilages. Top left and right Initial appearance. Middle left and right Release of middle alar cartilages and insertion of alar spreader graft. Bottom (left) Release of left upper lateral cartilage and insertion of spreader graft. Dorsal onlay graft and alar extension grafts are also in place

\section{PATIENTS AND METHODS}

Patients were defined as 'tertiary' if they had undergone two or more previous operations by one or more surgeons. Within this context, 'salvage' related to the severity of the deformity and the complexity of its repair.

The 26 cases comprised 18 females and eight males ranging from 24 to 43 years of age. Follow-up was a minimum of eight months and extended up to 34 months. Most patients had undergone two previous operations by the same surgeon. Seven patients had been operated on by two or more different surgeons. Fourteen of the primary or initial surgeons had been trained in plastic surgery, and 12 were trained in otolaryngology. In two patients, the open approach had been used both primarily and secondarily. In four, the open approach was used secondarily. All other operations had been carried out in a closed or endonasal fashion. 

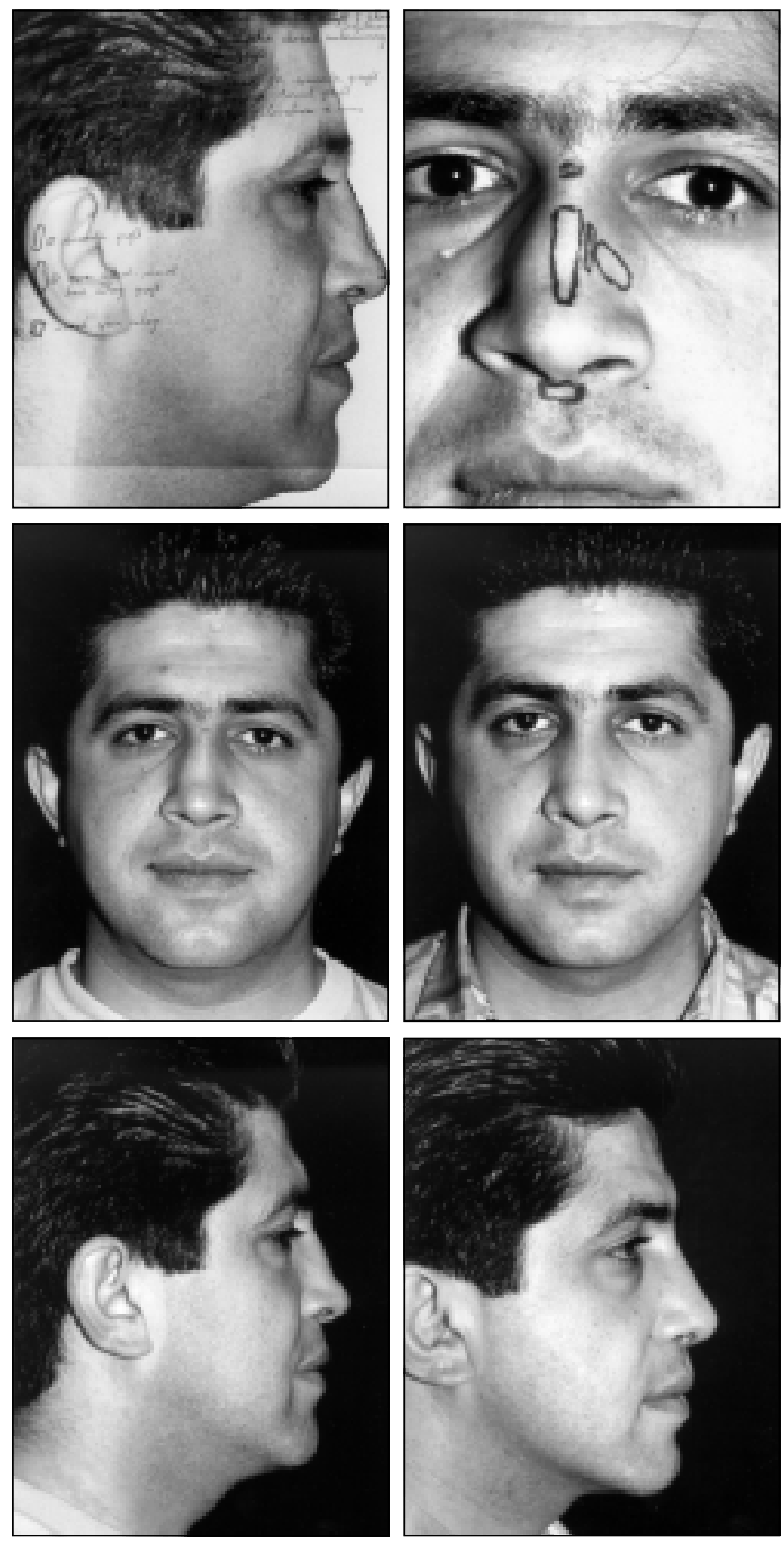

Figure 3) Case 2. Replacement of missing bone and cartilage. Top left and right Preoperative plans and drawings of anticipated grafts. Centre left and bottom left Preoperative views. Centre right and bottom right Postoperative views

\section{CASE PRESENTATIONS}

\section{Case 1}

A cosmetic rhinoplasty was performed on a patient who had had three previous surgeries (Figures 1,2). The primary correction was the release of contracted cartilages. Operating time was $5 \mathrm{~h}$. Postoperative photographs were taken at 21 months. Specifics of the procedure are as follows.

- Release of contracted middle alar cartilages and insertion of alar spreader graft (conchal cartilage).
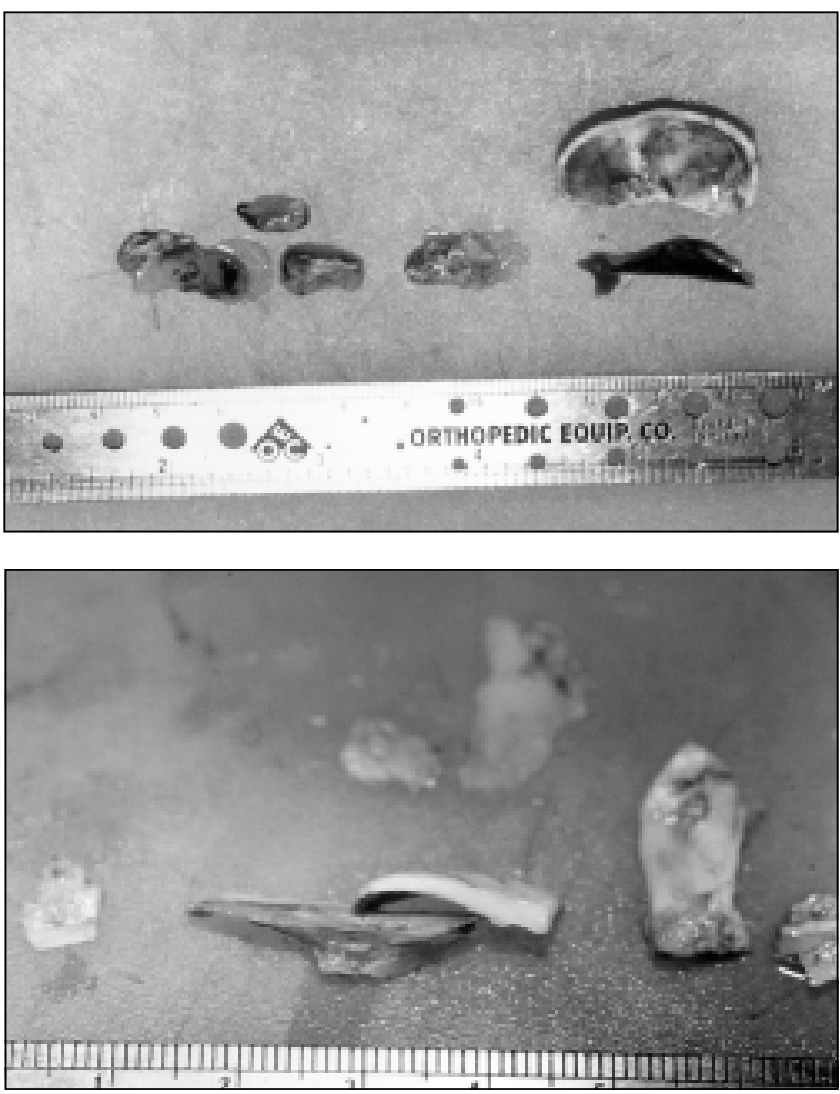

Figure 4) Case 2. Top Salvaged remnants of septum and conchal cartilage graft. Bottom Intraoperative grafts, left to right. Above are the left upper lateral spreader graft and left nasal bone/upper lateral cartilage onlay graft. Below are the radix grafts $\times 2$, dorsal grafts $\times 2$, columellar strut graft and nasal spine grafts $\times 2$

- Columellar strut graft (septal cartilage).

- Bilateral inferior alar rim extension grafts (conchal cartilage).

- Interdome suture.

- Release of contracted left upper lateral cartilage and insertion of dorsal spreader graft (conchal cartilage).

- Dorsal graft (single onlay septal cartilage - inferior third of dorsum).

- Bilateral lateral osteotomies.

\section{Case 2}

A post-traumatic rhinoplasty was performed on a patient who had had two previous surgeries (Figures 3,4). The primary correction was the replacement of missing bone and cartilage. Operating time was $4 \mathrm{~h}$. Postoperative photographs were taken at nine months. Specifics of the procedure are as follows.

- Cephalic trim of lateral crura.

- Columellar strut graft (conchal cartilage).

- Dome definition sutures. 

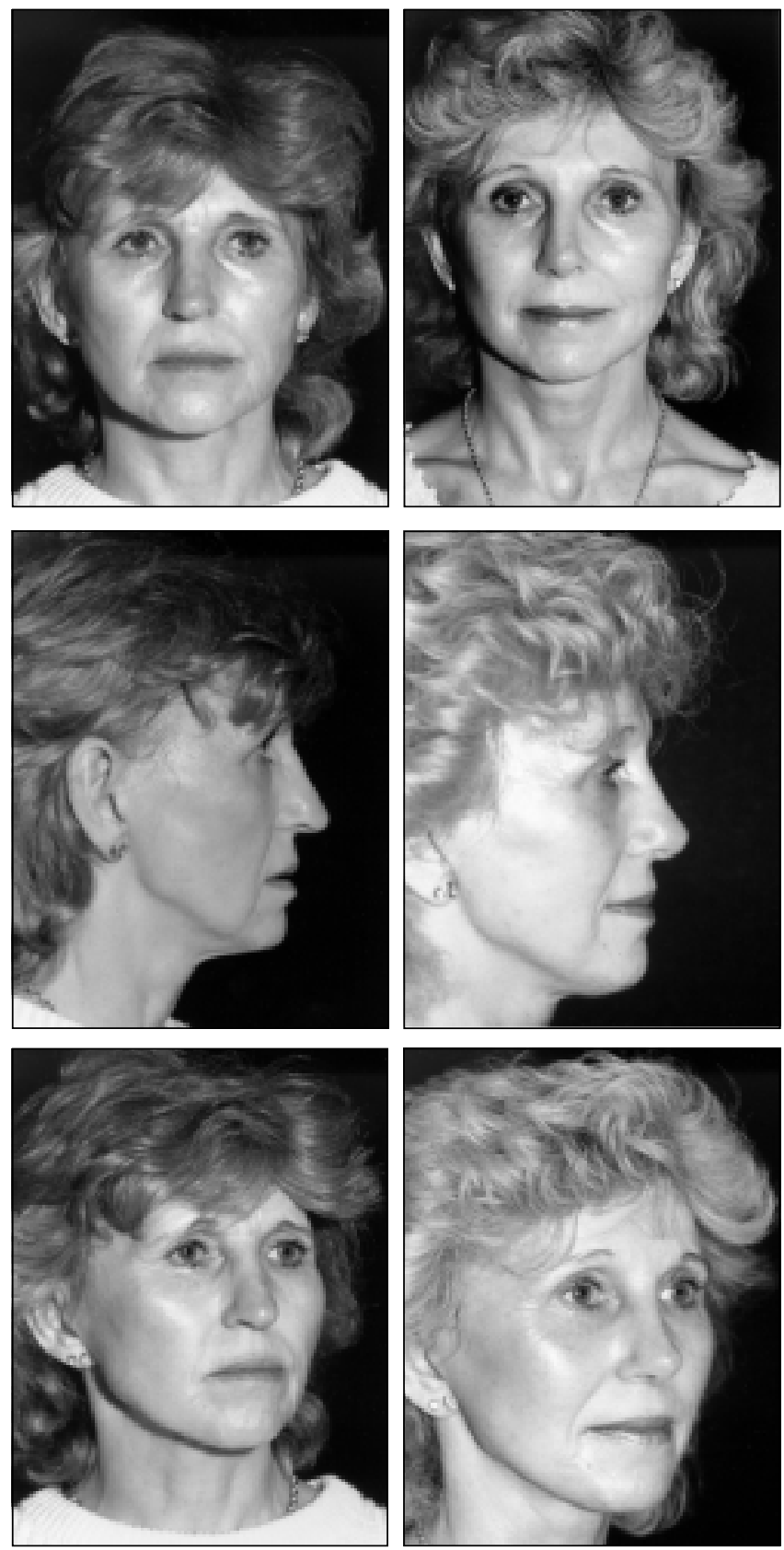

Figure 5) Case 3. Repositioning and reshaping of cartilage - facelift done during same opeation. Left Preoperative view. Right Postoperative view

- Interdome sutures to narrow tip.

- Anterior nasal spine graft (double onlay vomer bone).

- Radix graft (double onlay septal cartilage).

- Left upper lateral spreader graft (conchal cartilage).

- Left nasal bone and left upper lateral onlay cartilage graft (single onlay perpendicular plate bone to camouflage separation of upper lateral from nasal bone).
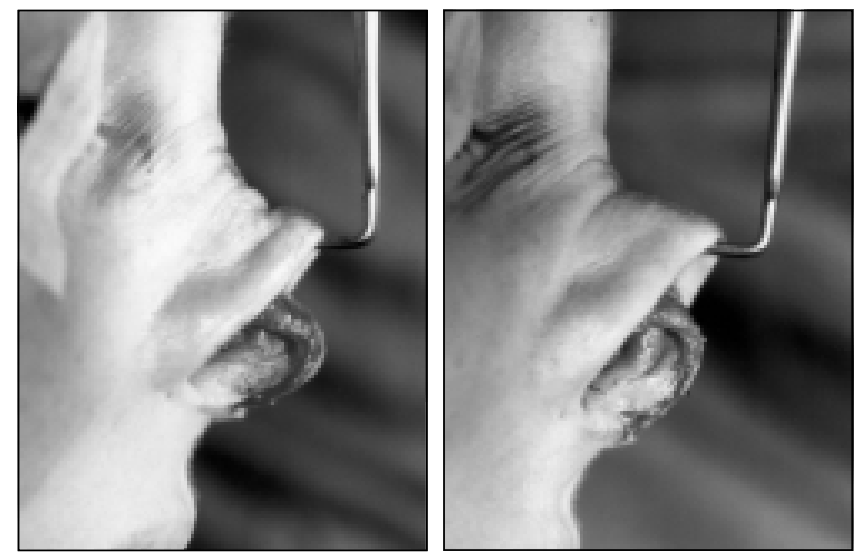

Figure 6) Case 3. Left Before cartilage repair. Right After cartilage repair

- Dorsal graft (double onlay combination of vomer bone, and conchal cartilage - inferior half of dorsum).

- Right lateral osteotomy.

\section{Case 3}

A cosmetic and post-traumatic rhinoplasty was performed on a patient who had had two previous surgeries (Figures 5,6). The primary correction was the repositioning and reshaping of cartilages. Operating time was $3 \mathrm{~h}$ (nose). Postoperative photographs were taken at 12 months. Specifics of the procedure are as follows.

- Cephalic trim of lateral crura.

- Release and superior rotation of right ala.

- Dome definition sutures.

- Interdome sutures to narrow tip.

- Medial crural-septal sutures to adjust tip rotation.

- Bony and cartilaginous dorsum reduced $0.5 \mathrm{~mm}$ with smoothening of irregularities.

- Bilateral lateral osteotomies.

- Septoplasty.

- Face lift (during same operation).

\section{Case 4}

Rhinoplasty was performed on a patient with a congenital defect (cleft lip nose) who had had two previous surgeries (Figures 7,8). The primary correction was reconstruction of tip cartilages. Operating time was $5 \mathrm{~h}$. Postoperative photographs were taken at 18 months. Specifics of the procedure are the following.

- Cephalic trim of lateral crura.

- Release and external rotation of right medial crus.

- Columellar strut graft (septal cartilage).

- Dome definition sutures. 

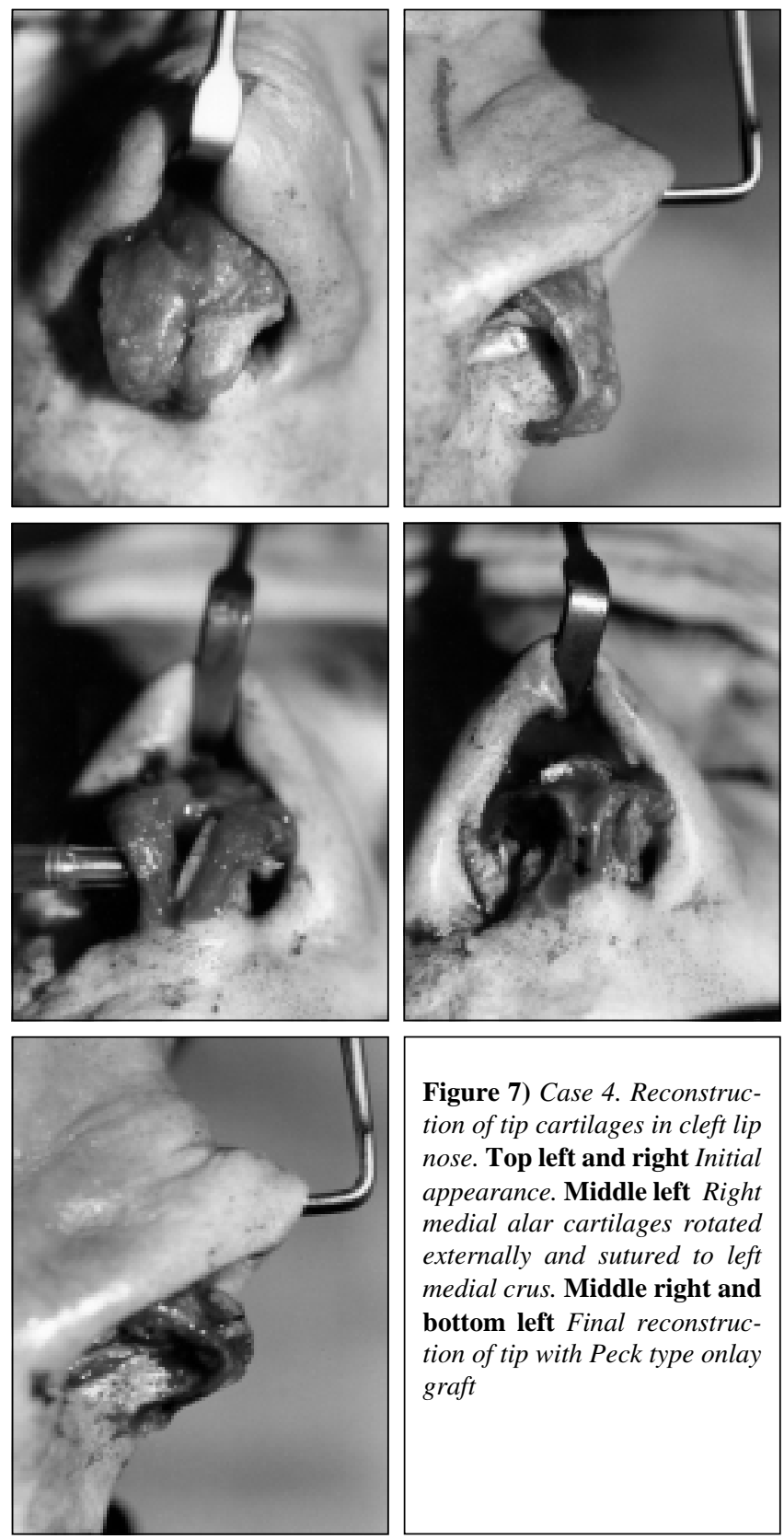

Figure 7) Case 4. Reconstruction of tip cartilages in cleft lip nose. Top left and right Initial appearance. Middle left Right medial alar cartilages rotated externally and sutured to left medial crus. Middle right and bottom left Final reconstruction of tip with Peck type onlay graft

- Interdome sutures to narrow tip.

- Lateral crural spanning sutures.

- Peck type middle alar graft (onlay conchal cartilage).

- Reduction of anterior nasal spine.

- Dorsal graft (double onlay septal cartilage - inferior third of dorsum).

- Bilateral lateral osteotomies.

- Septoplasty.
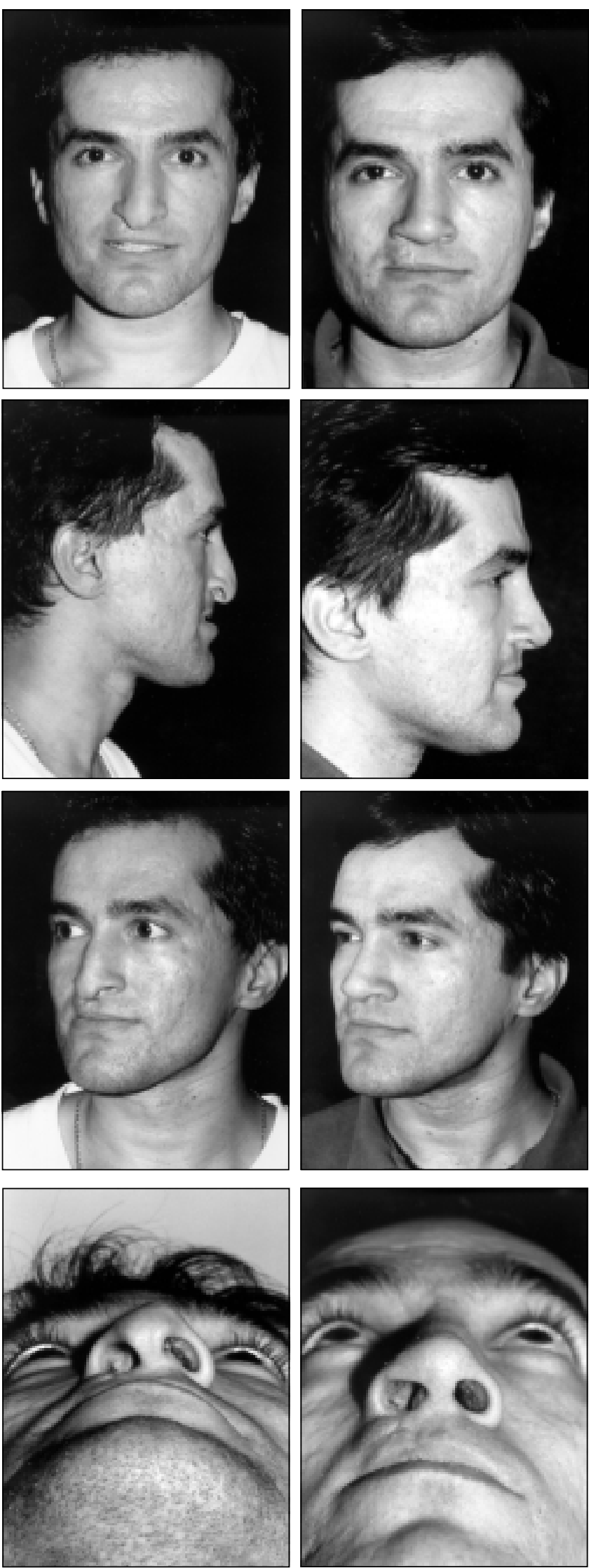

Figure 8) Case 4. Reconstruction of tip cartilages in cleft lip nose. Left Preoperative view. Right Postoperataive view 


\section{SURGICAL APPROACH}

From a surgeon's standpoint, revision rhinoplasty can be challenging, even when the surgery is redone by the primary surgeon. The patient, on the other hand, perceives the additional surgery to be minor, and tends to have high expectations. If the final result is still not satisfactory, the situation becomes difficult for both the surgeon and the patient. The significant technical problems that must be addressed are exacerbated by the emotional complexities of a strained patient-physician relationship.

Patient emotions: Patients consulting about tertiary rhinoplasties are generally nervous and confused, and feel very vulnerable. They may have emotions of anger and betrayal if the second operation made them look worse than the first. It is not uncommon for patients, most of whom are young and self-conscious, to become tearful during the initial consultation. They have images of a permanently deformed face, and worry about the potential costs of further surgery.

Close to one-quarter of the patients seen in consultation for tertiary rhinoplasty actually have a good cosmetic result. Some simply have overly perfectionistic expectations that need to be tempered with reality. They have to realize that minor irregularities in the dorsum and in the osteotomy lines are acceptable if they are only palpable and are not visible. Patients must also understand that nasal tip movement with smiling may not be surgically correctable. These individual concerns can usually be managed adequately with reassurance. Others within the group of satisfactory looking patients are unhappy because their nasal profile is not the one they had hoped for. In their perception, the dorsum is too low, or the nasal tip is rotated upward too much. Occasionally, patients complain of a loss of ethnicity. These patients are more difficult to deal with, and reassurance alone may not be sufficient. Additional surgery may be necessary. Such cases serve as a reminder of how necessary it is to understand clearly what the patient is hoping to achieve from surgery. In a diverse culture such as ours, there are many different perceptions of what constitutes an ideal nose.

When it is established that a true deformity still exists, a decision has to be made for or against further surgery. It may not be possible to decide this in the first visit. The patient's emotional stability has to be balanced with the severity of the deformity, and if concerns exist, a psychiatric consultation must be obtained. The greater the emotional liability of the patient, the more certain the surgeon must be that a distinct improvement is achievable. Once another operation is undertaken, all the remaining imperfections fall on the shoulders of the last surgeon.

It is noteworthy that most patients do not initiate litigation. While unhappy with their results, patients have a sense that the initial surgeon did his or her best, and that the complexity of the nasal deformity was very much responsible for the poor result. There is also a general acceptance that a certain percentage of patients require revisionary work. Only two of the patients in this series initiated legal action against their primary surgeon.
Preoperative planning: In the first visit, the characteristics of the nose and of the specifics of the deformity are documented. With the patient holding a mirror, each anatomic detail is carefully pointed out. Patients frequently fixate on one upsetting aspect of a nose, and are oblivious to other deformities - that is, until after surgery when a critical re-evaluation takes place.

Deficiencies and excesses of the dorsum and nasal tip are measured to the millimetre with a short, straight edge clear ruler. Malalignments and asymmetries are drawn on the patient's chart. Airflow studies may be needed for insurance purposes.

The septum is examined with a fibreoptic light. Almost all salvage procedures require cartilage grafts, and the amount of remaining septum is critical in the planning process. The size and shape of the ears is noted for potential conchal grafts.

Once it has been decided to go ahead with surgery, a full complement of colour slides and $8 \times 11$ " black and white photographs is taken. Oblique views more readily demonstrate asymmetries. The right lateral view (or left lateral if the surgeon operates from the left side) includes an enlarged full sized 1:1 enlargement. This photograph allows true direct measurements and is referred to frequently during surgery. The expertise of a well trained medical photographer is invaluable in the planning process of any rhinoplasty.

Every patient is seen at least once more before surgery. The need for realistic expectations is re-emphasized, and the actual anticipated improvement is downplayed to increase the likelihood of meeting the patient's expectations. The general plan and list of objectives are explained.

The day before surgery, an operative blueprint is marked out on tracing paper that is taped over the 1:1 photograph (Figure 3, top left). The desired profile is sketched with a fine leaded pencil. Keeping in mind the distinct wishes of the patient, 'artistic licence' may at times be necessary to correlate the measurements. The anticipated shape and size of cartilage and bone grafts are determined, and full-sized drawings of each graft are made on the sketch.

The fourth and final check of measurements is made when the patient is sitting on the operating room table. The position of each graft is then drawn on the skin at the site of the deficiency, and areas of bone or cartilage excess are appropriately marked.

Skin dissection: It is preferable to carry out a tertiary rhinoplasty under general anesthesia because of the lengthy surgery time and because the septum is typically involved in the procedure. To reduce bleeding, a hypotensive agent is used, and the base of the nose is infiltrated with xylocaine and adrenaline. The nasal tip and dorsum are not injected to minimize distortion.

Skin flap elevation is quite tedious and can take over half an hour. Fine, sharp scissors are required, and the dissection should always be performed in a cutting fashion. Freeing scarred skin with the blunt spreading of scissors should never be attempted - this tears the delicate cartilage and occasion- 
ally the skin. The tips of the scissors point downward towards the cartilage at all times, and the scar is released bit by bit with small cuts. The cartilage is constantly kept in view. It is important not to slide into a more superficial plane, which may damage the subdermal plexus of vessels and further thin out the skin.

The area just superior to the domes is the most critical for skin survival. I have seen three patients in consultation who have developed skin sloughs in this area. The dermis in this area is much thicker than that of the columella, and I suspect that skin ischemia occurs when the surgeon continues to dissect in the same superficial plane he or she started with in the thin columellar skin, which can occur easily because dermis and scar are indistinguishable. Unfortunately, this plane of dissection cuts through the subdermal plexus of vessels in the thicker skin and can cause ischemic necrosis. The problem is avoided by always maintaining a sharp surgical plane directly on the cartilage surface. When the cephalic edge of the domes is reached, the cutting scissors are angled downward, dissecting over the edge of the crura until the midline septum and upper laterals are exposed.

The dorsal skin dissection similarly hugs perichondrium and periosteum, keeping the skin flap as thick as possible. Lateral dissection in the tip region usually goes to the juncture of the lateral crura and accessory cartilages, and then extends superiorly in a triangular fashion to the radix.

Nasal tip surgery: After skin elevation, the cartilage anatomy in the nasal tip may be quite obscured. The scar tissue patiently has to be stripped from the cartilage surface and edges. Slowly, the structures become more exposed and definable; therein lies the true strength of the open approach. The deformity is clearly displayed, and an appropriate repair or reconstruction can then be performed.

The extent of damage that can be present from previous rhinoplasties is surprising. Invariably, it is worse than expected clinically. Cartilages can be rotated, contracted and gnarled, cephalic excisions of lateral crura can be asymmetrical, rim strips can be dislocated and torn, and segments of cartilage can be missing.

A common configuration is where one crus has been pulled down from its original attachment to the septum, with a unilateral and asymmetric loss of tip projection. Attempts at repair through the endonasal approach may involve artificially trying to lower the opposite normal crus with an additional cephalic rim resection, which in turn alters the level of the tip-defining point on that side. This creates another asymmetry without addressing the real problem. In the open approach, the deformity is corrected by repositioning the medial crura with sutures, and then trimming the rim strips and reshaping the domes as necessary (Figures 5,6). Final tip projection is determined with medial crural-septal sutures, with or without the use of a columellar strut.

More complicated tip problems may involve deficient or collapsed cartilage segments that require bridge grafts or supportive underlay grafts. Pinched tip deformities are managed with alar spreader grafts (Figures 1,2). Reconstructive
Peck or Sheen onlay type grafts may still be needed (Figures 7,8). Each graft is sutured into place.

Open septoplasty: The open septoplasty can be a major adjunct to the open approach. It provides access and a visual assessment of the dorsal and anterior supports of the septum. These structural pillars must be maintained, while the remaining septum is frequently harvested for graft material.

The medial crura are separated and a subperichondrial plane established on one or both sides of the septum with a Cottle elevator. Wide undermining is performed. A scalpel incises the septum anteriorly and dorsally, leaving a continuous L-shaped $1 \mathrm{~cm}$ pillar support. Bone cutters extend the graft length posteriorly into the perpendicular plate. The sharp end of the elevator releases the inferior edge from the vomerine crest and frees the posterior edge of the graft through multiple perforations of the thin perpendicular plate. All the salvageable remains of the septum can then be removed.

Dorsal septal deviations and deformities of the anterior pillar support are more readily corrected with the open approach. The cartilage is incised at the point of maximum angulation and straightened. It is then fixed in this position and reinforced with a sutured onlay spreader type of graft (2). In patients with a caudal dislocation, the base of the anterior pillar is released with a separate mucosal incision and is sutured directly to the nasal spine periosteum.

Nasal dorsum surgery: The nasal dorsum is rarely excessive in a tertiary or salvage rhinoplasty. Usually, it has been overresected, and a segmental or complete dorsal augmentation is required. Minor and moderate deficiencies of 1 to $3 \mathrm{~mm}$ can be managed with single or multilayered septal grafts, with or without conchal graft underlays. A previous submucous resection of the septum limits the options, and small pieces of septal cartilage may have to be sutured in a row onto the dorsum.

Conchal grafts can be used in isolation, but are irregular in thickness and contour, and more difficult to shape. For profound over-resections of the dorsum, cranial bone and rib grafts are used. Whenever possible, bone is augmented with bone graft, and cartilage with cartilage graft.

A number of patients require dorsal spreader grafts to widen functionally and aesthetically contracted internal valves (3). Two to $3 \mathrm{~mm}$ of widening is commonly required, and conchal cartilage can readily substitute for septum when the latter is a premium (Figures 1,2).

\section{DISCUSSION}

Traditional teaching in salvage or tertiary rhinoplasty has been based on a fairly conservative approach - limited undermining of tissue, minor adjustments of profile, and carefully contoured cartilage or bone grafts in small subcutaneous pockets $(1,4)$. This approach is still desirable in minor augmentation work (5). However, in more complex cases, the open approach appears to be more desirable (6-9). The generous undermining of an open rhinoplasty need not cause tissue 
compromise if performed correctly and done in appropriately selected patients. The skin release appears to provide a more natural redraping to the changed profile. The procedure should not be carried out in the presence of a scarred nasal tip or a dorsum with thin overlying skin.

The primary advantage of the open approach is in the accurate diagnosis of the deformity, and the ability to repair displaced and deformed cartilage elements in an anatomic fashion. This provides both an esthetic and functional correction. It is difficult to accomplish this with the endonasal technique, where the emphasis is on surface irregularities. The 'blind' undermining of skin, as performed with the endonasal approach, frequently occurs in a more superficial plane, further thinning tissue coverage. Potential grafts are thus more likely to be visible 12 months after surgery, when the swelling has settled. However, postoperative edema with the open approach may last somewhat longer than with the closed technique, and minor contour changes can still be seen up to 18 months after surgery.

The length of time necessary to perform this operation is of concern. The first few attempts at an open tertiary rhinoplasty may take over $5 \mathrm{~h}$, and I schedule at least $4 \mathrm{~h}$ for a difficult repair. Similar operating times have been confirmed with Drs J Tebbits and J Gunther (personal communication). The tedious disection is not as time consuming as is the variability of the deformity and its repair. Suturing of cartilage and graft placement both involve an element of trial and error, and adjustments and readjustments are frequently required. Millimetre asymetries are readily identified and need to be corrected.

The principles of salvage repair are similar, regardless of the original deformity. They apply to cosmetic, posttraumatic, and congenital problems (10). All contracted and scarred down cartilages need to be released (case 1), and in simple cases a repositioning, and reshaping of cartilages is adequate (case 3). In more extensive cases, over-resected segments of cartilage and bone have to be replaced (case 2), and occasionally new segments need to be reconstructed (case 4). It is helpful to classify patients according to the predominant component of repair, although there is an element of each in most cases.
The open approach tertiary rhinoplasty is not suited to every surgeon; it requires time and extreme patience. No matter how thorough the preoperative assessment and surgical planning, the procedure may still have to be changed once the actual deformity is exposed. The surgeon must be flexible, and have a clear concept of nasal anatomy and a clear understanding of alternative methods of repair. The ability to be creative is helpful.

When a pleasing result is obtained, the gratitude expressed by the patient is immeasurable and the lengthy time spent achieving the result becomes quite unimportant.

\section{REFERENCES}

1. Sheen JH. Problems in secondary rhinoplasty. In: Sheen JH, Sheen AP. Aesthetic Rhinoplasty. St Louis: Mosby, 1987:1134-409.

2. Ramierz OM, Pozner JN. The severely twisted nose. Treatment by separation of its components and internal cartilage splinting. Clin Plast Surg 1996;23:327-40.

3. Rohrich RJ, Hollier LH. Use of spreader grafts in the external approach to rhinoplasty. Clin Plast Surg 1996;23:255-63.

4. Meyer R. Secondary rhinoplasty. In: Gruber RP, Peck GC, eds. Rhinoplasty: State of the Art. St Louis: Mosby Year Book, 1993:221-36.

5. Daniel RK. Secondary rhinoplasty following open rhinoplasty. Plast Reconstr Surg 1995;96:1539-46.

6. Juri J. Salvage techniques for secondary rhinoplasty. In: Daniel RK, Regnault P, Goldwyn RM, eds. Asthetic Plastic Surgery: Rhinoplasty. Boston: Little, Brown \& Co, 1993:481-99.

7. Gruber RP, Friedman G. Secondary rhinoplasty (open approach). In: Gruber RP, Peck GC, eds. Rhinoplasty: State of the Art. St Louis: Mosby Year Book, 1993;237-54.

8. Gunter JP, Rohrich RJ. External approach for secondary rhinoplasty. Plast Reconstr Surg 1987;80:161-74.

9. Perkins SW, Tardy ME. External columellar incision approach to revision of the lower third of the nose. Facial Plast Surg Clin 1993;1:79-98.

10. Rifley W, Thaller SR. The residual cleft lip nasal deformity. An anatomic approach. Clin Plast Surg 1996;23:81-92.

This paper is dedicated to the memory of Dr Morris Siu Chong, who recently lost his life at an early age to cancer. He was a superb anesthetist, and a gentle man. He was a kind and constant supporter of my work with these patients. 